\title{
Análise de materiais de apoio no tema "Água" para professores e alunos do Ensino Fundamental I e II
}

\author{
ANALYSIS OF SUPPORT MATERIALS ON “WATER" THEME FOR TEACHERS AND STUDENTS OF BASIC EDUCATION
}

\author{
Deborah Terrell ${ }^{1}$, Priscila Pereira Coltrl ${ }^{2}$ \\ 1 - Mestre em ClênCias pelo Instituto de Geociências USP, Pesquisadora autônoma. \\ 2 - Diretora do Centro de Pesquisas Meteorológicas e Climáticas Aplicadas à Agricultura (Cepagri), Docente do Programa de Pós Graduação em Ensino e \\ História de Clências da Terra (PPG-EHCT), Universidade Estadual de Campinas, Campinas, SP, Brasil. Pesquisadora CNPQ. \\ E-MALL: DEHTERREL@@GMALl.COM, PCOLTRI@CPA.UNICAMP.BR.
}

\begin{abstract}
This research carried out a survey about the support materials on the theme "Water" available on the internet in digital format for students and teachers to use as a complement to textbooks and teacher notebooks. Three criteria were defined for the evaluation: content analysis, visual language and contextualization, in which values were assigned for the final classification. Of the total materials evaluated (31), $42 \%$ received a maximum score of 10 points, which showed the quality and interdisciplinarity of the materials available online but mainly aimed at students and teachers from Middle School. The use of support materials in the classroom together and textbook to teach the theme "Water" can enrich the teaching-learning process by presenting the complex theme in a contextualized, critical and practical way, essential for an education committed to a new water culture.
\end{abstract}

Resumo: Esta pesquisa realizou um levantamento acerca dos materiais de apoio no tema "Água" disponíveis na internet em formato digital para alunos e professores utilizarem de forma complementar aos livros didáticos e cadernos do professor. Foram definidos três critérios para a avaliação dos materiais: análise de conteúdo, linguagem visual e contextualização, tendo sido atribuídos valores para a classificação final. Do total de materiais avaliados (31), 42\% receberam pontuação máxima de 10 pontos que mostrou a qualidade e interdisciplinaridade dos materiais disponíveis on line, mas direcionados principalmente para alunos e professores do Ensino Fundamental II. A utilização de materiais de apoio em sala de aula em conjunto com o livro didático para 0 ensino do tema "Água" pode enriquecer o processo de ensino-aprendizagem ao apresentar o tema complexo de forma contextualizada, crítica e prática, essencial para uma educação comprometida com uma nova cultura da água.
Citation/Citação: Terrell, D., \& Coltri, P. P. (2021). Análise de materiais de apoio no tema "Água" para professores e alunos do Ensino Fundamental I e II. Terræ Didatica, 17(Publ. Contínua), 1-11, e021053. doi: 10.20396/td.v17i00.8667194.

Keywords: Interdisciplinarity, Contextualization, Complexity, Environmental Education, Science Education.

Palavras-chave: Interdisciplinaridade, Contextualização, Complexidade, Educação Ambiental, Educação Científica.

\section{Manuscript/Manuscrito:}

Received/Recebido: 15/10/2021

Revised/Corrigido: 26/10/2021

Accepted/Aceito: 03/12/2021

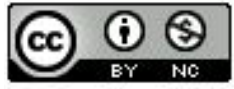

\section{Introdução}

A água é um tema de extrema relevância em nossa sociedade, pois dela dependem nossas principais funções sociais e de sobrevivência. Sua importância fica clara nos fundamentos da Política Nacional de Recursos Hídricos (PNRH, Brasil, 1997) que apresenta a água como um bem de domínio público e finito, rompendo o paradigma do uso da água dependente de sua disponibilidade, que por muitos anos cultivou uma cultura de desperdício. A gestão descentralizada e participativa proposta pela PNRH inovou com o estabelecimento dos comitês de bacias hidrográficas que une os poderes públicos, usuários e sociedade civil na gestão de recursos hídricos, representando um grande avanço na questão da gestão participativa da água.

Mesmo assim, nos dias de hoje, as sucessivas crises hídricas que estão ocorrendo de forma cada vez mais sistêmica, torna urgente para essa, e para as novas gerações, uma nova forma de agir e conviver com a água. É no contexto da gestão participativa que a Educação ganha espaço, pois é o caminho para a formação de novos cidadãos mais informados sobre sua atuação, não só como parte do problema, mas também, como parte da solução (Jacobi \& Grandisoli, 2017).

A educação dos alunos sobre o tema "Água" na escola ocorre por meio das componentes disciplinares do currículo e, de acordo com a nova Base Nacional Comum Curricular (BNCC) deve ser iniciado nas disciplinas de Ciências e Geografia na etapa do Ensino Fundamental I, tendo continuidade nas mesmas disciplinas do Ensino Fundamental II. Na etapa do Ensino Médio, o tema é abordado oficialmente nas áreas de Ciências Natureza e suas Tecnologias (Brasil, 2017). Santos \& Justina (2020) consideram que na BNCC os conhecimentos, as habilidades e as competências a serem alcançadas pelos estudantes a respeito do tema "Água" se referem ao reconhecimento de sua importância para a manutenção da vida no planeta, a presença e ausência de água, seus estados físicos, ciclo hidro-

\begin{tabular}{c|c|c|c|c|c}
\hline (C) Terrae Didat. & Campinas, SP & v.17 & $1-11$ & $\mathrm{e} 021053$ & 2021 \\
\hline
\end{tabular}


lógico, os usos da água na agricultura, na geração de energia, equilíbrio dos ecossistemas, problemas decorrentes do uso da água e os padrões de qualidade e potabilidade.

No entanto, o ensino desse tema nas escolas também ocorre por meio de projetos de Educação Ambiental, abordados de forma transversal, em um contexto interdisciplinar, democrático e participativo, tal como preconizado pela Politica Nacional de Educação Ambiental (Brasil, 1999). Trajber \& Mendonça (2006) destacam que, em todas as regiões do Brasil, "Água" foi o tema mais trabalhado em projetos de Educação Ambiental. Ao avaliar a inserção das temáticas ambientais em disciplinas curriculares, os autores observaram maior frequência do tema nas disciplinas de Ciências Naturais, sucedidas por Geografia.

O ensino formal do tema "Água" na sala de aula ocorre principalmente por meio dos livros didáticos, enquanto materiais físicos, disciplinares, fazem parte de coleções seriadas, pensadas para o cotidiano escolar. A análise da inserção do tema nos livros didáticos em diferentes disciplinas e graus de ensino reitera a importância do uso do livro didático como ferramenta de ensino, mas seu uso isolado e a apresentação do tema como pronto e definitivo, desvinculado do contexto histórico, social e cultural dos alunos pode representar um obstáculo na compreensão da importância do tema (Otalara, 2008, Piza \& Teran, 2011, Freitas \& Marin, 2015, Fonseca, 2019, e Menezes et al., 2020).

Piza \& Teran (2011) apontam que uma perspectiva estritamente disciplinar e não integradora sobre o tema resulta em uma ideia empobrecida. Otalara (2008) e Culpi (2016) alertam para o perigo do uso isolado do livro didático, podendo retratar uma visão pouco realista, descontextualizada e limitando-se a apresentar os produtos da ciência, e não sua história. O tema "Água" nos livros didáticos de Ciências e Geografia avaliados por Freitas \& Marin (2015) é problematizado de maneira pontual, sendo que alguns conceitos essenciais para a compreensão do assunto não são evidenciados. Como ponto positivo os autores destacam que as atividades nos livros didáticos analisados até contemplam a aquisição de conteúdos atitudinais, porém, os exemplares apresentam lacunas para a realização de atividades em grupo e de experimentações, principalmente no que tange a subsídios teóricos para a compreensão do tema.

Menezes et al. (2020) analisam que, apesar de os livros didáticos serem instrumentos importantes que podem auxiliar professores e estudantes na aprendizagem, ressaltam que o ensino da temática hídrica requer materiais de apoio como ferramenta sensibilizadora.

Para auxiliar o trabalho docente com o uso do livro didático, os professores utilizam material de apoio composto principalmente pelo caderno do professor que orienta o trabalho docente em sala de aula. Na pesquisa sobre a proposta curricular do Estado de São Paulo, Neira (2011) discorre que o caderno do professor do Estado de São Paulo orienta conteúdos, habilidades e competências por série/ ano, acompanhados de diretrizes para a gestão da sala de aula, para a avaliação e a recuperação, bem como sugestões de métodos e estratégias de trabalho nas aulas. De acordo com o autor, a utilização do caderno do professor de forma isolada pode levá-lo a abordar os conhecimentos de forma superficial e fragmentada; o tom informativo e instrumental, muitas vezes, sobrepõe-se a qualquer preocupação com o desenvolvimento de uma postura crítica por parte dos educadores e, consequentemente, dos educandos.

Os materiais didáticos são definidos nas escolas por critérios próprios de cada instituição, de acordo com seu projeto pedagógico, suas orientações de ensino e do currículo formal, quer sejam livros ou materiais de apoio, quer se destinem a professores ou a alunos. Na busca de materiais complementares de apoio para o ensino do tema "Água” os professores se deparam com uma infinidade de material, atualmente de aquisição facilitada a partir da tecnologia de livros digitais e da internet.

Esta pesquisa teve como objetivo avaliar um conjunto de materiais de apoio sobre o tema "Água" disponíveis na internet em formato digital (e-book) e apresentar sua relevância de forma a ajudar professores e alunos da educação básica (Ensino Fundamental I e II) no uso de materiais complementares ao livro didático e ao caderno do professor e, assim, contribuir para a inserção desse tema nas escolas em um contexto interdisciplinar, participativo e engajado para a formação de cidadãos atuantes na sociedade em que vivem.

\section{Materiais e Métodos}

Para a execução da pesquisa a metodologia de trabalho foi organizada em três fases: Fase 1 diagnóstico, Fase 2 - classificação e Fase 3 - análise final (Fig.1).

$\mathrm{Na}$ Fase 1 foi realizado o diagnóstico e seleção dos materiais disponíveis na internet do tipo e-books ou cartilhas digitais devido à facilidade de acesso e 


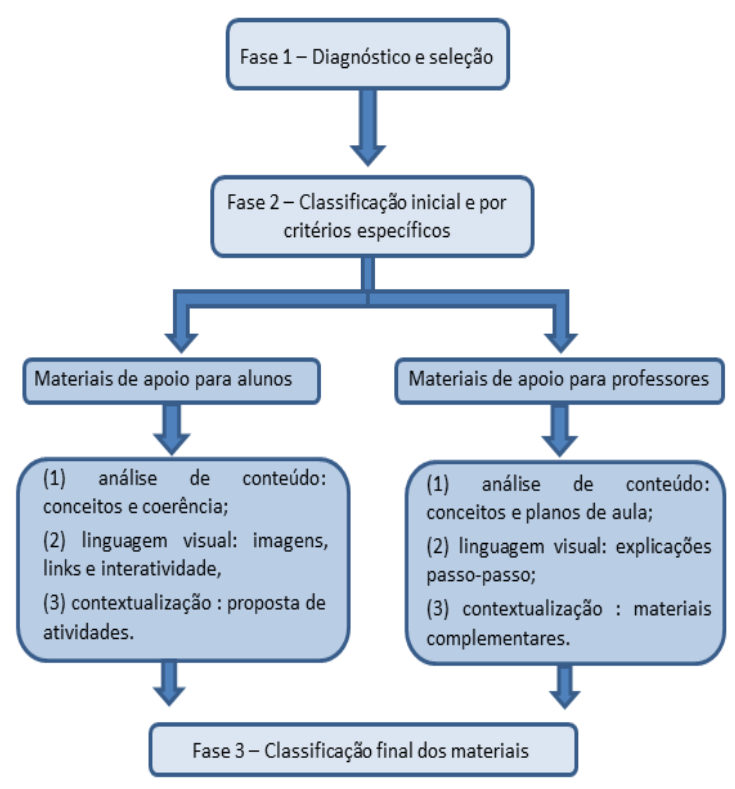

Figura 1. Roteiro metodológico da pesquisa livre download. A busca foi realizada no site de busca Google e em sites específicos, como das bibliotecas digitais da Agência Nacional das Águas - ANA e de Universidades, com cursos específicos para formação de professores. Palavras-chave como: água; recursos hídricos; materiais didáticos; materiais paradidáticos; ciclo da água e/ou ciclo hidrológico; águas subterrâneas; bacias hidrográficas e educação ambiental, de forma simples ou conjugadas, foram utilizadas na busca.

Nesta etapa foram selecionados um total de 31 (trinta e um) materiais que foram catalogados e organizados em planilha contendo: título, ano, autores/coordenadores da edição, entidade responsável, tipo indicado (aluno ou professor) e URL (Tab.1).

A fase 2 foi de classificação, na qual os materiais selecionados foram inicialmente divididos em dois grupos: (a) material de apoio para aluno e (b) material

Tabela 1. Materiais de apoio selecionados para classificação

\begin{tabular}{|c|c|c|c|c|c|}
\hline Título & Ano & $\begin{array}{c}\text { Autores/ } \\
\text { coord. }\end{array}$ & Entidade & Tipo & URL \\
\hline $\begin{array}{l}\text { Recursos hídricos } \\
\text { subterrâneos: nosso } \\
\text { maior tesouro. }\end{array}$ & 2007 & $\begin{array}{l}\text { Vitorino, A. R; } \\
\text { Costa, S. R. }\end{array}$ & ABAS & Alunos & $\begin{array}{l}\text { https://www.abas.org/arquivos/carti- } \\
\text { lha_rh.pdf }\end{array}$ \\
\hline $\begin{array}{l}\text { Água na medida } \\
\text { certa. }\end{array}$ & 2008 & $\begin{array}{l}\text { São Paulo - } \\
\text { Secretaria de } \\
\text { Meio Ambiente } \\
\end{array}$ & SMA/ SP & Alunos & $\begin{array}{l}\text { https://www.infraestruturameioambiente. } \\
\text { sp.gov.br/educacaoambiental/prateleira- } \\
\text {-ambiental/agua-na-medida-certa/ }\end{array}$ \\
\hline $\begin{array}{l}\text { Cartilha Meio } \\
\text { Ambiente: Infiltração }\end{array}$ & 2011 & $\begin{array}{l}\text { Lelis, A. C; } \\
\text { Carvalho, J. } \\
\text { C. de. }\end{array}$ & UnB & Alunos & $\begin{array}{l}\text { https://onedrive.live.com/?au- } \\
\text { thkey=\%21AGUMIN727Ir\%2D- } \\
\text { GWc\&cid=F008729B25F64FF0\&i- } \\
\text { d=F008729B25F64FF0\%2115817\&parId=- } \\
\text { F008729B25F64FF0\%2111052\&o=OneUp }\end{array}$ \\
\hline Povos das águas & 2017 & Silva, E. G. A. & UFPI & Alunos & $\begin{array}{l}\text { https://capacitacao.ana.gov.br/conhe- } \\
\text { cerh/bitstream/ana/2186/1/Cartilha\%20 } \\
\text { Povos\%20das\%20Aguas.pdf }\end{array}$ \\
\hline $\begin{array}{l}\text { Planeta Azul: guia de } \\
\text { atividades }\end{array}$ & 2017 & Santos, R. A. S. & FGB & Alunos & $\begin{array}{l}\text { http://www.fundacaogrupoboticario.org.br/ } \\
\text { pt/Biblioteca/Atividades\%203\%C2\%BA\%20 } \\
\text { ano\%20-\%20\%C3\%81gua.pdf }\end{array}$ \\
\hline $\begin{array}{l}\text { A história da água } \\
\text { no Brasil - do } \\
\text { descobrimento aos } \\
\text { nossos dias. Águas no } \\
\text { país das jabuticabas. }\end{array}$ & 2017 & Teixeira, C. A. & Unasp & Alunos & $\begin{array}{l}\text { https://capacitacao.ana.gov.br/conhecerh/ } \\
\text { handle/ana/2876 }\end{array}$ \\
\hline $\begin{array}{l}\text { Guardiões da } \\
\text { natureza: missão: em } \\
\text { busca da recuperação } \\
\text { da nascente. }\end{array}$ & 2017 & Fonseca, A. L. & Unifei & Alunos & $\begin{array}{l}\text { https://docplayer.com.br/53993742-Guar- } \\
\text { dioes-da-natureza-missao-em-busca-da- } \\
\text {-recuperacao-da-nascente.html }\end{array}$ \\
\hline Manual do rio Tietê & 1997 & $\begin{array}{l}\text { Bojadsen, M.I.; } \\
\text { Renard, M. }\end{array}$ & $\begin{array}{l}\text { ONG } 5 \\
\text { Elementos }\end{array}$ & Alunos & $\begin{array}{l}\text { https://5elementos.org.br/projeto/manual- } \\
\text {-do-rio-tiete/ }\end{array}$ \\
\hline $\begin{array}{l}\text { Água: Mudanças } \\
\text { ambientais globais. } \\
\text { Pensar + agir } \\
\text { na escola e na } \\
\text { comunidade. }\end{array}$ & 2008 & Czapski. S. & $\begin{array}{l}\text { Secad/ } \\
\text { MEC }\end{array}$ & Alunos & $\begin{array}{l}\text { http://www.educacao.go.gov.br/documentos/ } \\
\text { nucleomeioambiente/Caderno2_agua.pdf }\end{array}$ \\
\hline $\begin{array}{l}\text { Um mergulho na } \\
\text { bacia do APA - água, } \\
\text { natureza e educação } \\
\text { ambiental. }\end{array}$ & 2008 & $\begin{array}{l}\text { Medeiros, Y. } \\
\text { et. al. }\end{array}$ & UFMS & Alunos & $\begin{array}{l}\text { http://www.imasul.ms.gov.br/wp-content/ } \\
\text { uploads/2016/03/Cartilhapenaagua.pdf }\end{array}$ \\
\hline
\end{tabular}




\begin{tabular}{|c|c|c|c|c|c|}
\hline Água fonte de vida. & 2010 & Silva, L. Q. & $\begin{array}{l}\text { Fundação } \\
\text { Vitória } \\
\text { Amazônica }\end{array}$ & Alunos & $\begin{array}{l}\text { https://www.terrabrasilis.org.br/ecote- } \\
\text { cadigital/images/abook/pdf/Agua\%20 } \\
\text { Fonte\%20da\%20Vida.pdf }\end{array}$ \\
\hline Cartilha Infiltração. & 2010 & Carvalho, J. C. & UnB & Alunos & $\begin{array}{l}\text { https://onedrive.live.com/?au- } \\
\text { thkey=\%21APiEpZkjRg6WKXs\&- } \\
\text { cid=F008729B25F64FF0\&i- } \\
\text { d=F008729B25F64FF0\%2115819\&parId=- } \\
\text { F008729B25F64FF0\%2111052\&o=OneUp }\end{array}$ \\
\hline Recursos hídricos. & 2011 & $\begin{array}{l}\text { Rocha, G.A. } \\
\text { et. al. }\end{array}$ & SMA/SP & Alunos & $\begin{array}{l}\text { https://www.infraestruturameioambiente. } \\
\text { sp.gov.br/educacaoambiental/prateleira- } \\
\text {-ambiental/caderno-14-recursos-hidricos/ }\end{array}$ \\
\hline $\begin{array}{l}\text { As águas subterrâneas } \\
\text { do Estado de São } \\
\text { Paulo. }\end{array}$ & 2012 & $\begin{array}{l}\text { Iritani, M. A; } \\
\text { Ezaki, S. }\end{array}$ & SMA/SP & Alunos & $\begin{array}{l}\text { https://www.infraestruturameioambiente. } \\
\text { sp.gov.br/educacaoambiental/prateleira- } \\
\text {-ambiental/caderno-1-as-aguas-subterra- } \\
\text { neas-do-estado-de-sao-paulo/ }\end{array}$ \\
\hline $\begin{array}{l}\text { Atlas para a } \\
\text { sustentabilidade } \\
\text { ambiental na Bacia } \\
\text { do Alto Tietê: uma } \\
\text { aventura pelos seus } \\
\text { recursos naturais. }\end{array}$ & 2014 & Borba, M. P. & $\begin{array}{l}\text { ONG } 5 \\
\text { Elementos }\end{array}$ & Alunos & $\begin{array}{l}\text { http://www.5elementos.org.br/wp-con- } \\
\text { tent/uploads/2015/03/Atlas_para_a_Sus- } \\
\text { tentabilidade_da_Bacia_Hidrografica_do_- } \\
\text { Alto_Tiete-1-compressed.pdf }\end{array}$ \\
\hline $\begin{array}{l}\text { Pelas tramas da } \\
\text { cidadania: os recursos } \\
\text { hídricos em nossas mãos. }\end{array}$ & 2017 & $\begin{array}{l}\text { Lima, G. M. } \\
\text { et. al. }\end{array}$ & Uniube & Alunos & $\begin{array}{l}\text { https://capacitacao.ana.gov.br/conhecerh/ } \\
\text { handle/ana/298 }\end{array}$ \\
\hline $\begin{array}{l}\text { Água e comunidade. } \\
\text { Construindo } \\
\text { soluções sustentáveis. }\end{array}$ & 2017 & $\begin{array}{l}\text { Nascimento, A. } \\
\text { C. S. et al. }\end{array}$ & Unifesspa & Alunos & $\begin{array}{l}\text { https://capacitacao.ana.gov.br/conhecerh/ } \\
\text { handle/ana/2206 }\end{array}$ \\
\hline $\begin{array}{l}\text { Águas de Pesqueira: } \\
\text { conhecer para } \\
\text { conservar. }\end{array}$ & 2019 & $\begin{array}{l}\text { Silva, M. G. } \\
\text { L. da }\end{array}$ & UFPE & Alunos & $\begin{array}{l}\text { https://www.dropbox.com/s/iq3ndzdz- } \\
\text { 0lhjnxj/Cartilha\%20Aguas\%20de\%20Pes- } \\
\text { queira\%20\%281\%29.pdf }\end{array}$ \\
\hline $\begin{array}{l}\text { Planeta Azul: livro } \\
\text { do professor }\end{array}$ & 2017 & Santos, R, A. & FGB & Professor & $\begin{array}{l}\text { http://www.fundacaogrupoboticario.org. } \\
\text { br/pt/Biblioteca/Livro\%20do\%20pro- } \\
\text { fessor\%203\%C2\%BA\%20ano\%20-\%20 } \\
\text { \%C3\%81gua.pdf }\end{array}$ \\
\hline ODS6 & 2020 & $\begin{array}{l}\text { Moreira, T; } \\
\text { Santos, R. S. S. }\end{array}$ & UNESCO & Professor & $\begin{array}{l}\text { https://pt.unesco.org/fieldoffice/brasilia/ } \\
\text { expertise/education-sustainable-develop- } \\
\text { ment/eds-na-escola }\end{array}$ \\
\hline ODS14 & 2020 & $\begin{array}{l}\text { Moreira, T; } \\
\text { Santos, R. S. S. }\end{array}$ & UNESCO & Professor & $\begin{array}{l}\text { https://pt.unesco.org/fieldoffice/brasilia/ } \\
\text { expertise/education-sustainable-develop- } \\
\text { ment/eds-na-escola }\end{array}$ \\
\hline Caminho das águas & 2006 & $\begin{array}{l}\text { Sucupira, V. } \\
\text { A. B. }\end{array}$ & $\begin{array}{l}\text { FRM e } \\
\text { ANA }\end{array}$ & Professor & $\begin{array}{l}\text { https://capacitacao.ana.gov.br/conhecerh/ } \\
\text { handle/ana/2836 }\end{array}$ \\
\hline $\begin{array}{l}\text { Água para vida. Água } \\
\text { para todos }\end{array}$ & 2006 & $\begin{array}{l}\text { Barrêto, S. R; } \\
\text { Costa, L. }\end{array}$ & $\begin{array}{l}\text { WWF - } \\
\text { Brasil } \\
\end{array}$ & Professor & https://www.wwf.org.br/?2986/ \\
\hline Caderno das águas & 2008 & Altamirano, G. & PMSP & Professor & $\begin{array}{l}\text { https://www.prefeitura.sp.gov.br/cidade/se- } \\
\text { cretarias/upload/guia_aguas_1253304123.pdf }\end{array}$ \\
\hline $\begin{array}{l}\text { Água em curso - } \\
\text { multiplicadores }\end{array}$ & 2014 & $\begin{array}{l}\text { Agencia Nacio- } \\
\text { nal das Águas e } \\
\text { Ministério do } \\
\text { Meio Ambiente }\end{array}$ & $\begin{array}{l}\text { ANA/ } \\
\text { MMA }\end{array}$ & Professor & $\begin{array}{l}\text { https://capacitacao.ana.gov.br/conhecerh/ } \\
\text { handle/ana/935 }\end{array}$ \\
\hline $\begin{array}{l}\text { Os rios voadores, a } \\
\text { Amazônia e o clima } \\
\text { brasileiro }\end{array}$ & 2014 & $\begin{array}{l}\text { Moss, G; Moss, } \\
\text { M. }\end{array}$ & $\begin{array}{l}\text { Projeto } \\
\text { Rios Voa- } \\
\text { dores }\end{array}$ & Professor & $\begin{array}{l}\text { http://riosvoadores.com.br/wp-content/ } \\
\text { uploads/sites/5/2015/04/Caderno-Professor- } \\
\text {-Rios-Voadores-2015-INTERNETppp.pdf }\end{array}$ \\
\hline $\begin{array}{l}\text { Atlas para a } \\
\text { sustentabilidade } \\
\text { ambiental na Bacia } \\
\text { do Alto Tietê: uma } \\
\text { aventura pelos seus } \\
\text { recursos naturais. } \\
\text { Caderno de } \\
\text { atividades educativas }\end{array}$ & 2014 & Borba, M. P. & $\begin{array}{l}\text { ONG } 5 \\
\text { Elementos }\end{array}$ & Professor & $\begin{array}{l}\text { http://www.5elementos.org.br/wp-con- } \\
\text { tent/uploads/2015/03/Atlas_para_a_Sus- } \\
\text { tentabilidade_da_Bacia_Hidrografica_do_ } \\
\text { Alto_Tiete-1-compressed.pdf }\end{array}$ \\
\hline $\begin{array}{l}\text { Até debaixo d'água: } \\
\text { o uso consciente da } \\
\text { água e a prática do } \\
\text { nas escolas. }\end{array}$ & 2016 & Barbosa, M. & $\begin{array}{l}\text { Escola Su- } \\
\text { perior de } \\
\text { Artes Célia } \\
\text { Helena } \\
\end{array}$ & Professor & $\begin{array}{l}\text { https://capacitacao.ana.gov.br/conhecerh/ } \\
\text { handle/ana/2773 }\end{array}$ \\
\hline $\begin{array}{l}\text { Sobre a face das } \\
\text { águas: uma fonte } \\
\text { de inspiração } \\
\text { pedagógica sobre o } \\
\text { tema água }\end{array}$ & 2016 & $\begin{array}{l}\text { Nascimento, } \\
\text { C. C. et al. }\end{array}$ & UDESC & Professor & $\begin{array}{l}\text { https://capacitacao.ana.gov.br/conhecerh/ } \\
\text { handle/ana/2184 }\end{array}$ \\
\hline $\begin{array}{l}\text { Caixa de ciências. } 20 \\
\text { experimentos para uso } \\
\text { sustentável da água }\end{array}$ & 2017 & Borges, F. F. & $\begin{array}{l}\text { Instituto } \\
\text { Federal da } \\
\text { Paraíba } \\
\end{array}$ & Professor & $\begin{array}{l}\text { https://educapes.capes.gov.br/handle/ca- } \\
\text { pes/174542 }\end{array}$ \\
\hline $\begin{array}{l}\text { Água caderno do } \\
\text { educador }\end{array}$ & 2017 & Silva, R. S. & PUC RS & Professor & $\begin{array}{l}\text { https://capacitacao.ana.gov.br/conhecerh/ } \\
\text { handle/ana/2182?mode=full }\end{array}$ \\
\hline
\end{tabular}


de apoio para professores. Nesta etapa foram separados 18 (dezoito) materiais para alunos e 13 (treze) materiais para professores para avaliação classificatória específica realizada a partir de três categorias de análise: (1) análise de conteúdo, (2) linguagem visual e (3) contextualização, no qual foram atribuídos valores, conforme apresentado na Tabela 2.

A categoria análise do conteúdo foi avaliada a partir do conteúdo teórico e científico do material de apoio. A clareza e objetividade no tratamento do tema, assim como a abordagem de forma interdisciplinar e multidisciplinar também foram avaliados. Foi verificada a inserção dos principais conceitos relacionados com o tema "Água", tais como: ciclo das águas e/ou ciclo hidrológico, bacias hidrográficas, água subterrâneas, a disponibilidade da água, a gestão das águas, os conflitos e as soluções para a conservação da água, de forma integrada em seus aspectos naturais, sociais, culturais, econômicos e políticos.

O conteúdo científico também foi avaliado de acordo com o nível formativo indicado ou inserido (ex: Ensino Fundamental I ou II) e as diretrizes da BNCC, tais como: o reconhecimento da importância da água para a manutenção da vida no planeta, a presença e ausência de água, os estados físicos da água, ciclo hidrológico, os usos da água na agricultura, os usos da água na geração de energia, equilíbrio dos ecossistemas, problemas decorrentes do uso da água e os padrões de qualidade e potabilidade da água (Santos \& Justina, 2020).

A análise de conteúdo observou o tratamento do tema como "Água" ou "Recursos Hídricos", pois segundo Bacci \& Pataca (2008), a água passou a ser vista na sociedade como recurso hídrico e não mais como um bem natural, disponível para a existência humana e das demais espécies, passando a usá-la indiscriminadamente, encontrando sempre novos usos, sem avaliar as consequências ambientais em relação à quantidade e qualidade da água.

A categoria de linguagem visual ou recursos visuais representou um ponto fundamental na análise dos materiais de apoio, pois quanto mais clara a apresentação de figuras, imagens, mapas, quadros e tabelas, mais atrativos os temas se tornam às crianças e adolescentes, conforme preconizado por Belmiro (2000). Também foi avaliado se as imagens induziam preconceitos e estereótipos, fragmentação e à superficialidade da consciência sobre a realidade, conforme alertado por Souza (2021).

$\mathrm{Na}$ categoria de avaliação da linguagem visual também foi observado a inserção de ícones, boxes ou links que inserem conhecimentos complementares,
Tabela 2. Descrição dos critérios e valores utilizados para classificação dos materiais de apoio

\begin{tabular}{|c|c|c|}
\hline Critérios & \begin{tabular}{|c|} 
Síntese \\
descritiva
\end{tabular} & Valores \\
\hline \multirow{4}{*}{$\begin{array}{l}\text { Análise do } \\
\text { conteúdo }\end{array}$} & \multirow{4}{*}{$\begin{array}{l}\text { Coerência teórica } \\
\text { na apresentação } \\
\text { dos conceitos } \\
\text { científicos. } \\
\text { Apresentação do } \\
\text { tema de forma } \\
\text { interdisciplinar e } \\
\text { multidisciplinar. }\end{array}$} & 1 - Fraco \\
\hline & & 2 - Regular \\
\hline & & 3 - Bom \\
\hline & & 4-Ótimo \\
\hline \multirow{4}{*}{$\begin{array}{l}\text { Linguagem } \\
\text { visual }\end{array}$} & \multirow{4}{*}{$\begin{array}{l}\text { Qualidade na } \\
\text { apresentação visual } \\
\text { de figuras, imagens, } \\
\text { mapas, quadros e } \\
\text { tabelas de forma } \\
\text { atrativa. }\end{array}$} & 1 - Fraco \\
\hline & & 2 - Regular \\
\hline & & 3 - Bom \\
\hline & & 4 - Ótimo \\
\hline \multirow{2}{*}{ Contextualização } & \multirow{2}{*}{$\begin{array}{l}\text { Apresentação de } \\
\text { atividades em } \\
\text { situações cotidianas } \\
\text { e práticas, } \\
\text { contextualizadas e/ } \\
\text { ou experimentadas. }\end{array}$} & $\begin{array}{l}1 \text { - Não } \\
\text { contextuali- } \\
\text { zado }\end{array}$ \\
\hline & & $\begin{array}{l}2 \text { - Contex- } \\
\text { tualizado }\end{array}$ \\
\hline
\end{tabular}

adicionais ou mesmo indicações de referências mais aprofundadas sobre os temas abordados.

$\mathrm{Na}$ categoria de contextualização avaliamos o tratamento do tema de forma integrada com a realidade vivida como requisito essencial, pois as principais críticas referentes aos livros didáticos tradicionais se referem à descontextualização do tema "Água" no dia-dia dos alunos (Otalara, 2008, Piza \& Teran, 2011, Freitas \& Marin, 2015, Fonseca, 2019, e Menezes et al., 2020). Além disso, a inserção do tema para além do contexto local, ou seja, em seu contexto global é essencial para o entendimento da realidade complexa em que vivemos.

A contextualização dos temas com as realidades dos alunos e professores favorece a conscientização e reflexão acerca das questões do mundo real. Para Freire (1997) a conscientização implica que ultrapassemos a esfera espontânea de apreensão da realidade, para chegarmos a uma esfera crítica na qual a realidade se dá como objeto cognoscível e na qual o homem assume uma posição epistemológica. Além disso, discutindo problemas e assumindo responsabilidades na mudança, a escola realiza seu importante papel na construção social.

Por fim, a fase 3 consistiu na análise da classificação final dos materiais que receberam a maior pontuação (total de 10 pontos) que foram selecionados para apresentação e discussão neste trabalho, sendo 4 (quatro) materiais direcionados aos alunos e 9 (nove) materiais para professores.

\begin{tabular}{c|c|c|c|c|c}
\hline (C) Terrae Didat. & Campinas, SP & v.17 & $1-11$ & $\mathrm{e} 021053$ & 2021 \\
\hline
\end{tabular}




\section{Resultados}

Os resultados obtidos na avaliação classificatória específica mostraram que dos 31 (trinta e um) materiais avaliados $42 \%$ receberam pontuação máxima de 10 pontos; $13 \%$ receberam nota 9 ; $22 \%$ receberam nota 8 e $22 \%$ receberam nota 7 ou menos, o que evidencia a diversidade e a boa qualidade dos materiais disponíveis on line. Os materiais que receberam a pontuação máxima correspondem a $22 \%$ dos avaliados para alunos e $70 \%$ dos materiais para professores e apresentaram o tema de forma interdisciplinar e multidisciplinar, com figuras, imagens, mapas, quadros e tabelas e atividades em situações cotidianas e práticas, contextualizadas e/ ou experimentadas.

Dos materiais avaliados para apoio de alunos que receberam a pontuação 9 ou menos, de modo geral apresentaram boa pontuação no conteúdo científico e na linguagem visual, apresentando geralmente deficiência na questão da contextualização dos temas, a partir da aproximação dos conteúdos com a realidade prática dos alunos. Nos materiais avaliados para professores, a maior parte recebeu pontuação máxima, e dos $30 \%$ que receberam 9 ou menos pontos as deficiências observadas dizem respeito às questões de conteúdo científico e linguagem visual. No quesito contextualização, no entanto, todos os materiais se apresentaram de forma contextualizada, com a apresentação de atividades em situações cotidianas e práticas e experimentadas. A seguir são apresentados os resultados específicos na avaliação dos materiais para alunos e para professores.

\section{Materiais de apoio para alunos}

No total, foram avaliados 18 (dezoito) materiais de apoio para alunos e desse total, 39\% são destinados aos alunos do Ensino Fundamental I e 61\% para alunos do Ensino Fundamental II.

Dos materiais avaliados $22 \%$ receberam a nota máxima de $10(\mathrm{dez})$ pontos que corresponde a 4 (quatro) materiais, $11 \%$ receberam 9 (nove) pontos (2 materiais), $27 \%$ receberam 8 (oito) pontos (5 materiais) e $38 \%$ receberam 7 (sete) ou menos pontos (7 materiais). Na Tabela 3 é apresentada uma síntese dos resultados obtidos na avaliação dos materiais de apoio para alunos.

Dos 7 (sete) materiais direcionados aos alunos do Ensino Fundamental I, apenas 1 (um) recebeu a classificação máxima de 10 pontos, a cartilha: "Meio Ambiente: Infiltração", elaborada pela Faculdade de Tecnologia, Programa de pós-graduação em
Geotecnia, da Universidade de Brasília de 2012. Nela, são apresentados conceitos básicos sobre a água, ciclo hidrológico, a interação solo-água, as estruturas de infiltração da água, os direitos e deveres do cidadão e também sobre os conceitos chave da Educação Ambiental. Apresenta formas de educar ambientalmente a criança, e conclui que a interação entre o meio ambiente e a água deve ser harmoniosa e que cada criança pode contribuir para isso, ou seja, uma motivação atitudinal. A cartilha também se destaca por apresentar atividades interativas, jogos e experimentos de forma lúdica, mas com rigor científico, adequadas às crianças do Ensino Fundamental I.

Dos 11 (onze) materiais orientados para alunos do Ensino Fundamental II, 3 (três) deles receberam a nota máxima de 10 pontos, sendo eles: a cartilha "Infiltração" elaborada por pesquisadores da Faculdade de Tecnologia - Programa de pós-graduação em Geotecnia, da Universidade de Brasília; "Atlas para a sustentabilidade ambiental na Bacia do Alto Tietê: uma aventura pelos seus recursos naturais" da ONG 5 Elementos: Instituto de Educação e Pesquisa Ambiental e "Pelas tramas da cidadania: os recursos hídricos em nossas mãos", da Universidade de Uberaba (Uniube).

A cartilha "Infiltração" (2010) apresenta conceitos técnicos e complexos para além daqueles tratados nos livros didáticos. Mas os temas da "infiltração da água", "águas pluviais", "erosão" e "inundação" são apresentados aos alunos do Ensino Fundamental II com linguagem acessível. No critério contextualização, a cartilha apresenta medidas para a redução do escoamento superficial e também tipos de estruturas de infiltração (ex: poços de infiltração ou bacias de sedimentação) que podem resultar em experimentos a serem replicados nas escolas.

O "Atlas para a sustentabilidade ambiental na Bacia do Alto Tietê: uma aventura pelos seus recursos naturais" (2014) de autoria da ONG 5 Elementos: Instituto de Educação e Pesquisa Ambiental apresenta os conhecimentos básicos sobre a água e trata o tema de forma específica à Bacia do Alto Tietê em São Paulo na questão da gestão das águas, da poluição ambiental e nas práticas sustentáveis por meio da aprendizagem social. A apresentação visual dos dados é dinâmica e organizada, além da edição apresentar uma lista de filmes e curtas metragens para o aprofundamento no tema e um Caderno de Atividades específico para apoio ao professor, que também foi avaliado a seguir. 
Tabela 3. Resultados obtidos na classificação dos materiais de apoio para alunos

\begin{tabular}{|c|c|c|c|c|c|c|}
\hline Título & $\begin{array}{c}\text { Nível } \\
\text { formativo }\end{array}$ & Ano & Conteúdo & Linguagem & Contexto & Total \\
\hline $\begin{array}{l}\text { Recursos hídricos subterrâneos - Nosso } \\
\text { maior tesouro }\end{array}$ & Fund. I & 2007 & 4 & 2 & 1 & 7 \\
\hline Água na medida certa & Fund. I & 2008 & 4 & 3 & 1 & 8 \\
\hline Cartilha Meio Ambiente: Infiltração & Fund. I & 2011 & 4 & 4 & 2 & 10 \\
\hline Povos das águas & Fund. I & 2017 & 4 & 3 & 1 & 8 \\
\hline Planeta Azul: guia de atividades & Fund. I & 2017 & 3 & 4 & 2 & 9 \\
\hline $\begin{array}{l}\text { A história da água no Brasil - do descobri- } \\
\text { mento aos nossos dias. Águas no país das } \\
\text { jabuticabas }\end{array}$ & Fund. I & 2017 & 3 & 3 & 1 & 7 \\
\hline $\begin{array}{l}\text { Guardiões da natureza: Missão: Em busca da } \\
\text { recuperação da nascente }\end{array}$ & Fund. I & 2017 & 3 & 3 & 1 & 7 \\
\hline Manual do rio Tietê & Fund. II & 1997 & 4 & 1 & 2 & 7 \\
\hline $\begin{array}{l}\text { Água: Mudanças ambientais globais. Pensar } \\
+ \text { agir na escola e na comunidade. }\end{array}$ & Fund. II & 2008 & 4 & 4 & 1 & 9 \\
\hline $\begin{array}{l}\text { Um mergulho na bacia do APA - água, natu- } \\
\text { reza e educação ambiental. }\end{array}$ & Fund. II & 2008 & 3 & 3 & 1 & 7 \\
\hline Água: fonte de vida & Fund. II & 2010 & 2 & 2 & 1 & 5 \\
\hline Cartilha infiltração & Fund. II & 2010 & 4 & 4 & 2 & 10 \\
\hline Recursos hídricos & Fund. II & 2011 & 4 & 3 & 1 & 8 \\
\hline As águas subterrâneas do Estado de São Paulo & Fund. II & 2012 & 4 & 3 & 1 & 8 \\
\hline $\begin{array}{l}\text { Atlas para a sustentabilidade ambiental na } \\
\text { Bacia do Alto Tietê: uma aventura pelos seus } \\
\text { recursos naturais }\end{array}$ & Fund. II & 2014 & 4 & 4 & 2 & 10 \\
\hline $\begin{array}{l}\text { Pelas tramas da cidadania: os recursos hídri- } \\
\text { cos em nossas mãos }\end{array}$ & Fund. II & 2017 & 4 & 4 & 2 & 10 \\
\hline $\begin{array}{l}\text { Água e comunidade. Construindo soluções } \\
\text { sustentáveis }\end{array}$ & Fund. II & 2017 & 3 & 3 & 1 & 7 \\
\hline Águas de Pesqueira: conhecer para conservar & Fund. II & 2019 & 4 & 3 & 1 & 8 \\
\hline
\end{tabular}

A cartilha "Pelas tramas da cidadania: os recursos hídricos em nossas mãos" (2017) foi elaborada no âmbito do Programa de Apoio à Produção de Material Didático para a Educação Básica - Projeto Água da Agência Nacional de Águas (ANA) e CAPES/MEC pela Universidade de Uberaba (Uniube) e apresenta o tema com rigor científico. Fornece subsídios para que cada estudante busque a construção do conhecimento explorando o seu meio socioambiental. Os temas base são tratados em quatro capítulos: "água na natureza”, "os usos da água", "a disponibilidade hídrica e a qualidade das águas" e "cuidando das águas", com a apresentação de complementos mais aprofundados, experimentos, reflexões, além da indicação outros materiais multimídias desenvolvidos pelo projeto, tais como jogos virtuais, vídeos e aplicativo para celular.

\section{Materiais de apoio para professores}

Em relação aos materiais específicos para o trabalho do professor foram avaliados 13 (treze) materiais, sendo 23\%, para alunos do Ensino Fundamental I e 76\% para alunos do Ensino Fundamental II. De modo geral todos os materiais avaliados apresentaram boa pontuação sendo que, $70 \%$ do total receberam a pontuação máxima 10 (dez), $15 \%$ recebeu a nota 9 (nove) e $15 \%$ recebeu a nota 8 (oito). Na Tabela 4 é apresentada uma síntese dos resultados obtidos na avaliação dos materiais de apoio para professores.

Para alunos do Ensino Fundamental I, foram selecionados 3 (três) materiais, sendo que 2 (dois) receberam pontuação 10 (dez); são eles os dois volumes do Educação para o Desenvolvimento Sustentável ODS 6 - Água e saneamento e ODS 14 - Vida na água.

\begin{tabular}{c|c|c|c|c|c}
\hline (C) Terrae Didat. & Campinas, SP & v.17 & $1-11$ & $\mathrm{e} 021053$ & 2021 \\
\hline
\end{tabular}


A coleção "Cadernos de Educação para o Desenvolvimento Sustentável na Escola" é composta por nove livros, que contempla oito dos Objetivos para o Desenvolvimento Sustentável - ODS e um livro introdutório. Foi elaborada pelo setor de Educação da UNESCO no Brasil em 2020 com objetivo de divulgar a Educação para o Desenvolvimento Sustentável (EDS) e a Agenda 2030 para estudantes dos anos iniciais do ensino fundamental. O volume ODS 6 - Água e saneamento busca conscientizar os professores e as crianças sobre o ODS6 de "Assegurar a disponibilidade e gestão sustentável da água e o saneamento para todos". As práticas são direcionadas nos temas: "água como direito humano", "a água e o saneamento", "distribuição da água no Brasil", "gestão das águas como chave para a paz" e um dos diferenciais desse material é a discussão acerca da escassez hídrica e a crise hídrica no país. O caderno apresenta ideias para ação docente com propostas pedagógicas como práticas para conscientização dos estudantes sobre a importância de suas ações, individuais e coletivas, para a transformação local e planetária e uma lista de referências para consulta sobre o tema.

O volume ODS14 - Vida na água pretende conscientizar os professores e as crianças sobre o ODS14 de "Promover a conservação e o uso sustentável dos oceanos, dos mares e dos recursos marinhos para o desenvolvimento sustentável”. As práticas são direcionadas nos temas: "oceanos fonte de vida na Terra", "a proteção entra na pauta mundial”, "a influência em nossas vidas e as ameaças aos mares e oceanos". Assim como o volume ODS6, o volume ODS14 também apresenta as ideias para ação e uma lista de referências.

Dos 10 (dez) materiais destinados aos professores do Ensino Fundamental II, 7 (sete) receberam a pontuação 10 (dez), o que evidencia a diversidade e boa qualidade dos materiais disponíveis na internet. São eles: "Caminho das águas- Caderno do professor 1 e 2", "Água para vida, água para todos (cadernos 1 e 2)" " "Os rios voadores, a Amazônia e o clima brasileiro", o caderno de atividades educativas do "Atlas para a sustentabilidade ambiental na Bacia do Alto Tiete: Uma aventura pelos seus recursos naturais", "Caixa de ciências - Água - 20 experimentos para uso sustentável da água”, "Sob a face das águas” e "Água - caderno do Educador", que são descritos a seguir.

Os cadernos "Caminho das águas- Caderno do professor 1 e 2" (2006) são o fruto de um projeto realizado em parceria entre a Fundação Roberto Marinho (FRM) e a Agência Nacional de Águas (ANA) para o desenvolvimento de atividades educativas ligadas à temática da água. É composto por dois volumes que oferece ao professor alguns instrumentos didáticos para a iniciação dos alunos do Ensino Fundamental II nos procedimentos da pesquisa

Tabela 4. Resultados obtidos na classificação dos materiais de apoio para professores

\begin{tabular}{|c|c|c|c|c|c|c|}
\hline Título & $\begin{array}{l}\text { Nivel } \\
\text { formativo }\end{array}$ & Ano & Conteúdo & Linguagem & Contexto & Total \\
\hline $\begin{array}{l}\text { Planeta Azul - caderno do professor e caderno } \\
\text { de atividades }\end{array}$ & Fund. I & 2017 & 3 & 4 & 2 & 9 \\
\hline $\begin{array}{l}\text { Educação para o desenvolvimento sustentável. } \\
\text { ODS } 6 \text { - Água potável e saneamento }\end{array}$ & Fund. I & 2020 & 4 & 4 & 2 & 10 \\
\hline $\begin{array}{l}\text { Educação para o desenvolvimento sustentável. } \\
\text { ODS } 14 \text { - Vida na água }\end{array}$ & Fund. I & 2020 & 4 & 4 & 2 & 10 \\
\hline Caminho das águas- Caderno do professor 1 e 2 & Fund. II & 2006 & 4 & 4 & 2 & 10 \\
\hline Água para a vida Água para todos (cadernos 1 e 2 ) & Fund. II & 2006 & 4 & 4 & 2 & 10 \\
\hline Caderno das águas & Fund. II & 2008 & 3 & 4 & 2 & 9 \\
\hline Água em curso - multiplicadores & Fund. II & 2014 & 3 & 3 & 2 & 8 \\
\hline Os rios voadores, a Amazônia e o clima brasileiro & Fund. II & 2014 & 4 & 4 & 2 & 10 \\
\hline $\begin{array}{l}\text { Atlas para a sustentabilidade ambiental na Bacia } \\
\text { do Alto Tietê. Caderno de atividades educativas }\end{array}$ & Fund. II & 2015 & 4 & 4 & 2 & 10 \\
\hline $\begin{array}{l}\text { Até debaixo d'água - O uso consciente da água } \\
\text { e a prática do teatro nas escolas }\end{array}$ & Fund. II & 2016 & 4 & 2 & 2 & 8 \\
\hline Sobre a face das águas & Fund. II & 2016 & 4 & 4 & 2 & 10 \\
\hline $\begin{array}{l}\text { Caixa de ciências - Água. } 20 \text { experimentos para } \\
\text { uso sustentável da água }\end{array}$ & Fund. II & 2017 & 4 & 4 & 2 & 10 \\
\hline Água: caderno do educador & Fund. II & 2017 & 4 & 4 & 2 & 10 \\
\hline
\end{tabular}


científica - observação, experimentação e registro e exemplos concretos que poderão ser adaptados à realidade local, como planejar atividades educativas de alcance social na escola e na comunidade.

"Água para vida, água para todos" (2006) é um caderno educativo composto por dois volumes: o livro das águas e o guia de atividades e foi elaborado pela ONG WWF Brasil. O livro das águas é composto por dez capítulos e traz um conjunto de informações sobre a situação das águas no país e visa estimular a pesquisa, a vontade de conhecer e de participar no seu cuidado e gestão. O guia de atividades sugere uma série de ações e práticas para sensibilizar, construir conhecimentos, despertar a criatividade ao lidar com questões ambientais e chamar pessoas e grupos à ação pelo meio ambiente.

O caderno do professor "Os rios voadores, a Amazônia e o clima brasileiro" (2014) é um guia didático fruto do projeto "Expedição Rios Voadores" do aviador Gérard Moss com o apoio financeiro do Programa Petrobrás Socioambiental que apresenta de forma didática os temas "rios voadores", "serviços ambientais prestados pela floresta Amazônica", "o ciclo hidrológico" e a "savanização da Amazônia" para os professores, e propõe 4 atividades práticas para aplicação do tema em aula para alunos do Ensino Fundamental II.

O caderno de atividades educativas do "Atlas para a sustentabilidade ambiental na Bacia do Alto Tiete: Uma aventura pelos seus recursos naturais" da ONG 5 Elementos: Instituto de Educação e Pesquisa Ambiental (2015) apresenta nove atividades-aula voltadas aos alunos do Ensino Fundamental II e Médio. As atividades são interdisciplinares e trata desde conceitos básicos acerca do tema, tal como o funcionamento das bacias hidrográficas como perspectivas críticas com o futuro das águas.

O material "Caixa de ciências - Água - 20 experimentos para uso sustentável da água” (2017) foi elaborado pelo Instituto Federal da Paraíba e financiado a partir do Edital ANA-CAPES/DEB No 18/2015 - Programa de Apoio à Produção de Material Didático para a Educação Básica - Projeto Água da Agência Nacional de Águas (ANA) e CAPES/MEC, dentro da abordagem da Alfabetização Científica. Apresenta 20 experimentos para abordar conceitos importantes sobre o tema "água", por meio do uso de materiais simples, como sucatas, de baixo custo e alta disponibilidade, agrupados fisicamente em uma caixa como um kit facilmente transportável e replicável nas escolas ou mesmo nas casas dos estudantes.
"Sob a face das águas" (2017) foi elaborado por pesquisadores do Centro de Educação a Distância (CEAD) da Universidade do Estado de Santa Catarina (Udesc) com objetivo de associar a água com diferentes manifestações artísticas e culturais (textos, charges, músicas, fotos, esculturas, vídeos, entre outros). O material elabora propostas pedagógicas problematizadoras voltadas, tanto para a aprendizagem sobre a importância da água e do seu uso sustentável, quanto para a abordagem interdisciplinar em torno do tema. O projeto também foi executado no âmbito do Programa de Apoio à Produção de Material Didático para a Educação Básica, Projeto Água da Agência Nacional de Águas (ANA) e CAPES/MEC.

“Água - caderno do Educador" (2017) consiste em uma coleção de planos de aula elaborados por educadoras de instituições públicas do município de Gravataí, Rio Grande do Sul, a partir do Projeto Escola Sustentável: captação da água da chuva como elemento educador financiado pelo Edital ANA-CAPES/DEB No 18/2015 - Programa de Apoio à Produção de Material Didático para a Educação Básica - Projeto Água da Agência Nacional de Águas (ANA) e CAPES/MEC. As catorze propostas são destinadas ora para alunos do Ensino Fundamental II ora para o Ensino Médio, em um contexto interdisciplinar, com propostas e projetos participativos que instigam o questionamento dos alunos sobre a água, uso, consumo e apropriação.

\section{Discussão}

O uso de materiais de apoio complementares ao ensino em sala de aula pode contar com excelentes guias para a abordagem de tópicos complexos, como os documentos analisados nesta pesquisa, que constituem materiais especializados e de aprofundamento em diferentes temas, entre eles os temas ambientais, interdisciplinares e multidimensionais, ou seja, aqueles que devem ser tratados conjuntamente por diferentes disciplinas, tal como o tema "Água".

A temática da água, de acordo com Jacobi et.al (2018), traz consigo enorme potencial didático-pedagógico e de transformação, pois serve como eixo aglutinador para temas como alimentação, consumo consciente, manutenção da biodiversidade e serviços ecossistêmicos, saneamento, entre tantos outros. Tal fato, certamente, colabora para a realização de um trabalho verdadeiramente interdisciplinar focado na complexidade dos atores e processos ambientais, sociais, culturais e políticos. 
Mas como a abordagem do tema "Água" na escola ocorre principalmente por meio das componentes disciplinares de Ciências e da Geografia nos Ensinos Fundamental I e II, o tratamento disciplinar do tema, com o uso isolado dos livros didáticos e dos cadernos do professor, pode apresentar lacunas ao ensino que ao dissecar e aborda-lo de forma fragmentada acaba reduzindo o assunto, ou mesmo distanciando da realidade cotidiana dos alunos.

Nos dias de hoje é indiscutível a importância da educação no tema "Água" e, de acordo com Bacci \& Pataca (2008) a complexidade que envolve o tema na escola exige do professor uma capacidade de explorar o ambiente de forma contextualizada.

De acordo com Morin (1999) temas complexos devem ser tratados tanto no seu contexto local, mas também no seu contexto global, mostrando as relações entre o todo e as partes, porque o planeta Terra é o todo ao mesmo tempo organizador e desorganizador de que fazemos parte. Na pesquisa valorizamos o tratamento interdisciplinar e contextualizado do tema "Água". Na maior parte dos materiais de apoio para alunos e na totalidade dos materiais de apoio para professores avaliados verificamos a existência de propostas de atividades em grupo e experimentações que estimulam a responsabilidade pelo uso sustentável da água.

A grande maioria dos materiais avaliados é destinada ao Ensino Fundamental II e, em menor número, ao Ensino Fundamental I. Tal constatação mostra uma preocupação maior na disponibilização e tratamento do tema "Água" com alunos e professores do Ensino Fundamental II, em detrimento de materiais específicos para alunos e professores do Ensino Fundamental I.

Os professores que atuam no Ensino Fundamental II possuem Licenciatura em disciplinas específicas e tem sua formação quantitativamente superior nas diferentes áreas de conhecimento e menos enfatizada nas questões pedagógicas (Pimenta et al., 2017). Ao lecionar suas disciplinas, os professores especialistas devem aprofundar os temas de ensino, mas em uma prática disciplinar, que pode levar a uma ciência reducionista, ao privilegiar apenas algumas das faces dos temas complexos e multidimensionais e acabar contribuindo para uma educação simplificada. De acordo com Morin (1999) a hiperespecialização impede tanto a percepção do global (que ela fragmenta em parcelas) quanto do essencial (que ela dissolve).

Os professores que atuam no Ensino Fundamental I são formados em Licenciatura em Pedagogia e atuam como polivalentes, apesar desta denominação não aparecer mais na legislação brasileira. Na práti- ca, sua formação permite lecionarem as diferentes disciplinas básicas: língua portuguesa (alfabetização), história, geografia, ciências e matemática, mas nos cursos de formação inicial ainda prevalece um enfoque disciplinar, em detrimento ao conhecimento integrador, que leva a fragmentar e fragilizar a formação do pedagogo para atuar nos anos iniciais do Ensino Fundamental (Pimenta et al., 2017).

Se faz necessário, portanto, uma análise crítica sobre o currículo de formação dos professores especialistas e polivalentes, para, assim, contribuir para uma prática interdisciplinar que seja mais assertiva e direcionada às questões ambientais urgentes e necessárias e para que possibilite a apresentação dos temas complexos para os alunos compreenderem a importância de suas ações e atuações no mundo. Segundo Freire (1996) a educação é uma forma de intervenção no mundo, exige comprometimento, disponibilidade para o diálogo e acima de tudo querer bem aos educandos.

Por fim, a pesquisa reconheceu a existência de um grande número de materiais disponíveis na internet no tema "Água", sendo que parte deles é fruto de projetos de extensão universitária ou iniciativas de fundações ou organizações da sociedade civil. Muitos dos materiais de qualidade derivaram de financiamento público como o Programa de Apoio à Produção de Material Didático para a Educação Básica, como o Projeto Água da Agência Nacional de Águas (ANA), e CAPES/MEC de 2015 ou do Fundo Estadual de Recursos Hídricos de São Paulo (Fehidro), o que torna claro que políticas públicas de incentivo à produção de materiais didáticos ou de apoio à educação promovem uma educação de qualidade imprescindível para a melhoria da qualidade de vida das crianças e jovens, assim como de toda a população do nosso país.

\section{Considerações finais}

Esta pesquisa realizou um levantamento acerca dos materiais de apoio no tema "Água" disponíveis na internet em formato digital (e-book) para professores e alunos que podem ser utilizados de forma complementar na sala de aula e enriquecer o aprendizado sobre o tema.

Na escola o tratamento do tema "Água" de forma disciplinar pode apresentar falhas ao reduzir o tema complexo e multidimensional, distanciando os alunos de sua realidade tanto em seu contexto, como em seu complexo global.

A incorporação de materiais de apoio na educação de alunos e professores pode enriquecer processo de 
ensino-aprendizagem ao apresentar o tema contextualizado, de forma interdisciplinar, crítica e prática e assim estimular nos alunos mudanças de estilo de vida, aquisição de valores, habilidades, atitudes e incentivar os professores o debate, o exercício e a criação de práticas pedagógicas transformadoras para a construção de sociedades mais sustentáveis.

Todos os materiais estudados nesse trabalho ficarão disponíveis on line, no site do Cepagri da Unicamp, para consultas futuras de professores, escolas e do público interessado.

Ressalta-se que, nos dias de hoje, para além da escola, o tema "Água" deve ser dialogado com toda sociedade, a partir de um debate socioambiental urgente, tanto por conta das incertezas geradas pelas mudanças climáticas globais, mas também pela corresponsabilização de cada ator social na gestão adequada da água. Nesse sentido a educação é essencial para que crianças e jovens se sintam responsáveis e assim atuem de forma cada vez mais consciente, na condição de protagonistas para a mudança na convivência com a água.

\section{Referências}

Bacci, D. C., \& Pataca, E. M. (2008). Educação para a água. Estudos Avançados 22 (63). URL: https://www.scielo.br/j/ea/a/4Cz7B6yQGGfV73Ngy6g848w/?lang $=$ pt. Acesso 11.08.2021.

Belmiro, C. A. (2000). A imagem e suas formas de visualidade nos livros didáticos de Portuquês. Educação \& Sociedade, 21(72). doi: 10.1590/S0101-73302000000300002. Acesso 29.11.2021

Brasil. (1997). Lei No 9.433/1997.Politica Nacional de Recursos Hídricos. URL: http://www.planalto.gov.br/ ccivil 03/leis/19433.htm. Acesso 13.08.2021.

Brasil. (19999). Lei N / 9.795/1999. Política Nacional de Educação Ambiental. URL: http://www.planalto.gov.br/ ccivil 03/leis/19795.htm. Acesso 13.08.2021.

Brasil. Ministério da Educação. (2018). Base Nacional Comum Curricular: versão final. Brasília, DF: MEC. URL: http://basenacionalcomum.mec.gov.br/images/BNCC_EI_EF_110518_versaofinal_site.pdf Acesso 02.08.20 $\overline{2} 1$.

Culpi, V. L. F. L. (2016). Contribuições da pegada hídrica para o ensino de ciências: percepções e perspectivas de mudanças a partir da sala de aula. Curitiba: Universidade Tecnológica Federal do Paraná. Programa de PósGraduação em Formação Científica, Educacional e Tecnológica. 125p. (Dissert. Mestrado).

Fonseca, S. S. (2019). Produção de material didático como ferramenta pedagógica para educação Ambiental: abordagem da temática hídrica. Brasília: PROFBIO: Universidade de Brasília. 132p. (Dissert. Mestrado).

Freire, P. (1996). Pedagogia da autonomia. Os saberes necessários à prática educativa. São Paulo: Paz e Terra. 76p.

Freire, P. (1997). Pedagogia da esperança. Um reencontro com a pedagogia do oprimido. Rio de Janeiro: Paz e Terra. $127 \mathrm{p}$.

Freitas, N. T. A., \& Marin, F. A. D. G. (2015). Livros didáticos e o tema água: implicaçôes no trabalho docente. Curitiba: XII Congresso Nacional de Educação (Educere). URL: https://educere.bruc.com.br/arquivo/ pdf2015/16907 9456.pdf. Acesso 25.05.2021.

Jacobi, P. R., \& Grandisoli, E. (2017). Água e sustentabilidade: desafios, perspectivas e soluções. São Paulo: IEEUSP e Reconectta. 112p.

Jacobi, P. R, Empinotti, V., \& Grandisoli, E. (2018). Alternativas para o futuro da água em São Paulo. In: Buckeridge, M., \& Ribeiro, W. C. (2018). Livro branco da agua. A crise hídrica na Região Metropolitana de São Paulo em 2013-2015: Origens, impactos e soluções. São Paulo: Instituto de Estudos Avançados. 175p.

Menezes, J. P. C., Fonseca, S. S., \& Pedreira, A. J. L. A. (2020). Uma análise teórica sobre a temática hídrica em livros didáticos de Biologia do PNLD 2018. Uberlândia: Ensino Em Re-Vista, 27(3). URL: http:// educa.fcc.org.br/pdf/ensino/v27n3/1983-1730-ensino-27-03-1155.pdf. Acesso 16.06.2021.

Morin, E. (1999). Os sete saberes necessários à educação do futuro. São Paulo: Cortez. Brasília, DF: UNESCO. $102 \mathrm{p}$.

Neira, M. G. (2011). A proposta curricular do Estado de São Paulo na perspectiva dos saberes docentes. São Paulo: Rev. bras. Educ. Fís. Esporte, 25, 23-27. URL: https://edisciplinas.usp.br/pluginfile.php/236269/ mod resource/content $/ 0 / \mathrm{SP} \% 20 \mathrm{faz} \% 20$ escola $\% 20$ texto\%203.pdf. Acesso 15.11.2021.

Otalara, A. P. (2008). O tema água em livros didáticos de ciências de primeira a quarta séries do ensino fundamental. Rio Claro: Inst. Biociências, UNESP. 134p. (Dissert. Mestrado).

Pimenta, S. G., Fusari, J. C., Pedroso, C. C. A., \& Pinto, U. A. (2017). Os cursos de licenciatura em pedagogia: fragilidades na formação do professor polivalente. São Paulo, Educação e Pesquisa, 43(1), 15-30. URL: https://www.revistas.usp.br/ep/article/view/128191. Acesso 17.09.2021.

Piza, A. A. P., \& Terán, A. F. (2011). O tema água nos livros didáticos de ciências e geografia do $6^{\circ}$ ano do ensino fundamental. Manaus: Avanços e Desafios em Processos de Educação em Ciểncias na Amazônia. URL: http://m.espacosnaoformais.com.br/_files/200 001289-dc1cfdd173/2011 0219 Livro\%20Avancos $\% 20$ O $\% 20$ TEMA $\% \overline{2} 0 \%$ C $\overline{3} \% 81$ GUA $\% 20$ NOS $\% 20$ LIVROS $\% 20$ DID $\%$ C3\%81TICOS $\% 20$ DE\%20CI\%C3\%8ANCIAS-200-212.pdf. Acesso 15.11.2021.

Santos, N. Q., \& Justina, L. A. D. (2020). O tema "Água" nos anais do Encontro Nacional de Pesquisa em Educação em Ciências. Hipátia, 5(1), 155-167. URL: https://ojs.ifsp.edu.br/index.php/hipatia/article/ download/1449/990/. Acesso 13.07.2021.

Souza, J. V. R. As imagens nos livros didáticos de Geografia: trajetórias e significados. Campinas: Boletim Campineiro de Geografia. URL: http://agbcampinas.com.br/bcg/ index.php/boletim-campineiro/article/view/429. Acesso 15.11.2021.

Trajber, R., \& Mendonça, P. R. (2006). Educação na diversidade: o que fazem as escolas que dizem que fazem educação ambiental. Brasília, DF: Ministério da Educação (MEC), Secretaria de Educação Continuada, Alfabetização e Diversidade. 262p. 